\title{
La voluntad de poder como postulado epistemológico en el pensamiento de Nietzsche
}

\author{
Jorge Alfonso Chávez Gallo \\ Departamento de Filosofía \\ Universidad Autónoma de Aguascalientes \\ jachag@correo.uaa.mx
}

Para Nietzsche esto es lo fundamental: que somos algo que vive, que, en consecuencia, pensamos, creemos, imaginamos, sabemos, queremos, únicamente en tanto que vivientes; en tanto que somos no sólo vida, sino una forma determinada de vida. En resumen: «El 'ser' - nosotros no tenemos de ello ninguna otra representación que ‘vivir'. ¿Pues cómo puede algo muerto 'ser'?» ${ }^{1}$. En efecto, ¿cómo podríamos representarnos la muerte, la nada, si vivimos, si somos, en el sentido señalado? ¿Y de dónde más podríamos extraer noción alguna del ser sino de la vida misma, dado que vivimos? Nietzsche parece señalar con esta idea a la cuna de tal noción, caracterizándola sin embargo como una representación, y desterrando de esa forma todo carácter metafísico, trascendental, de ella: así, o el ser de los metafísicos es una nada conceptual, una abstracción completamente vacía, o bien, por otro lado, podemos representárnoslo, y en ese caso hunde sus raíces en la vida; es decir, es en todo caso él mismo, como idea, una manifestación de la vida, de una forma de vida en particular, y en ese sentido también un síntoma de ella.

De lo anterior es indesligable la postura a la que Nietzsche llama perspectivismo, cuyas líneas generales encontramos trazadas ya

${ }^{1}$ Friedrich Nietzsche, El nihilismo: escritos póstumos, trad. Gonçal Mayos, Barcelona: Península 2000, p. 35. KSA, 12, 2 [172]. 
en el escrito temprano Sobre verdad y mentira en sentido extramoral. Conforme a ella, el mundo empírico es una ilusión no menos que otro mundo cualquiera (el de las ideas - Platón-, el de la libertad -Kant-, por ejemplo, aunque en un sentido distinto, como se verá), porque está constituido por lo que esta forma particular de vida que somos ve, y es lo que necesita ver para vivir. La lógica, el número, el tiempo y el espacio, la causalidad, son ficciones creadas por el hombre en la medida en que las necesita para vivir, para ser. La vida ve siempre únicamente su interés, podría decirse que se ve siempre únicamente a sí misma. Pero, y esto es algo que tiene que ser subrayado, vivir no es sólo mantenerse con vida, no es meramente sobrevivir. Esto constituye uno de los motivos principales de la caracterización de la vida como voluntad de poder por parte de Nietzsche: lo vivo quiere ser más, y no sólo seguir siendo lo que es.

Ahora bien, de todo lo anterior no concluye Nietzsche, pirrónicamente, que no es posible conocer sino que, por el contrario, la toma de conciencia acerca de estas limitaciones (para decirlo á la Kant), es lo que propiamente hace posible el conocimiento, pues únicamente así éste se vuelve honesto: no tiene sentido suponer un mundo más real que el denominado 'mundo de la apariencia', postular un 'mundo verdadero' en oposición a éste, una 'realidad real' valga la expresión, 'trascendente', puesto que, en todo caso, no la conocemos como tal. La postulación de tal mundo constituye lo contrario a la honestidad exigida por Nietzsche, y en ese sentido constituye una mentira: «El mundo 'aparente' es el único: el 'mundo verdadero' no es más que un añadido mentiroso...»².

Nietzsche no afirma que el mundo aparente lo sea en contraposición a una supuesta realidad que lo trascienda, sino en relación

2 Friedrich Nietzsche, Crepúsculo de los ídolos, trad. Andrés Sánchez Pascual, Madrid: Alianza Editorial 2000, p. 52. KSA, 6, p. 75. 
a otras posibles 'apariencias': al mundo visto por otras formas de vida, esto es, desde otras perspectivas. De hecho, el 'mundo verdadero' ha debido ser inferido del 'mundo aparente', constituye su negación y parte por ende de él; dicho de otra manera, niega la realidad y finge otra. Pero, ¿es eso lo razonable cuando lo que se pretende es conocer? «Si la existencia de un mundo tal estuviese tan bien probada, se establecería entonces, sin embargo, que precisamente su conocimiento sería el más indiferente de todos: más indiferente todavía que para el navegante acosado por la tempestad debe serlo el conocimiento del análisis químico del agua» ${ }^{3}$. En consecuencia, habrá que decir que, a fin de cuentas: «no hay hechos, solamente interpretaciones» ${ }^{4}($ los hechos se constituyen como tales a través de las interpretaciones de lo único a lo que podemos llamar realidad, como se verá más adelante).

De acuerdo a lo anterior, la distinción entre sujeto y objeto pierde los matices tradicionales: ni uno ni otro es algo en sí ni por sí, sino que sólo se cuenta con lo que habría entre ellos, a saber, el 'fenómeno', las perspectivas, las interpretaciones. «¿Definitivamente es necesario poner al intérprete detrás de la interpretación? Eso es ya poesía, hipótesis» ${ }^{5}$. De acuerdo a esto no hay 'una' verdad, un único punto de arribo del conocimiento, sino una enorme pluralidad de ellos. Conocer no puede significar descubrir esa única realidad, sino abordar diversas perspectivas, la mayor cantidad posible de ellas (lo cual se traduce, a su vez, en una forma de vida mucho más compleja, con muchas más posibilidades pero, también, con otras tantas necesidades).

\section{III}

No es lo mismo, pues, la ficción natural, necesaria mejor dicho, del hombre (y de cualquier forma de vida), que la mentira (aun en

${ }^{3}$ Friedrich Nietzsche, Humano, demasiado humano, vol. 1, trad. Alfredo Brotons, Madrid: Ediciones Akal 2001, p. 47 (af. 9). KSA, 2, p. 29.

${ }^{4}$ Nietzsche, El nihilismo..., p. 60. KSA, 12, 7 [60].

${ }^{5}$ Nietzsche, El nihilismo..., p. 60. KSA, 12, 7 [60]. 
sentido extramoral). El conocimiento, tal como Nietzsche lo entiende, tiene su mayor obstáculo en la mentira, y en cambio hace uso de la ficción inevitable (incluso para superarla, para que nuevas ficciones sean posibles); mientras que el conocimiento entendido como búsqueda de aquella verdad trascendente pretendía (fingía) oponerse a la ficción, sólo que mediante la mentira. Ahora bien, en tanto que la ficción es necesaria para la vida, la 'voluntad de verdad' resulta contraria a la misma, alimentándose de la mentira, por lo cual también resulta un obstáculo para el conocimiento. «La 'verdad' es por consiguiente más funesta que el error y la ignorancia porque bloquea las fuerzas que podrían trabajar en favor de la ilustración y el conocimiento ${ }^{6}$. El conocer honesto postulado por Nietzsche, en cambio, parte de la vida, por lo que «la falsedad de un juicio [en aquél otro sentido] no es para nosotros ya una objeción contra él (...) La cuestión está en saber hasta qué punto ese juicio favorece la vida» ${ }^{7}$. En este contexto, las ficciones más necesarias son no sólo los juicios sintéticos a priori. En Nietzsche, la pregunta kantiana acerca de la posibilidad de estos juicios se transforma en la pregunta por la necesidad que ha tenido el hombre de creer en ellos.

\section{IV}

Aún hoy podría preguntarse por el papel de la ciencia desde este punto de vista. Por un lado, es claro que ella presupone esas ficciones, que ella misma es su consecuencia, su refinamiento. Es decir, que la ciencia presupone una interpretación de la realidad. Por otro lado, esto constituye ya la respuesta a la pregunta por la regularidad de la naturaleza, por la posibilidad de la predicción: las formas que descubrimos en la naturaleza «las producimos en nosotros y a partir de nosotros», de modo que «si estamos obligados a concebir todas las cosas solamente bajo esas formas, entonces

${ }^{6}$ Nietzsche, El nihilismo..., p. 154. KSA, 13, 15 [46].

7 Friedrich Nietzsche, Más allá del bien y del mal, trad. Andrés Sánchez Pascual, Madrid: Alianza Editorial 2000, p. 25. KSA, 5, p. 18. 
no es ninguna maravilla el que, a decir verdad, sólo captemos en todas las cosas precisamente esas formas (...)» ${ }^{8}$. Esto mismo, entre paréntesis, se sigue de la crítica de Kant a la razón pura, sólo que Nietzsche lo plantea de manera distinta, a saber: lo que la ciencia descubre en la naturaleza había sido ya introducido en ella por nosotros mediante el lenguaje, tema éste que sin embargo no cabe en el presente texto. En Sobre verdad y mentira en sentido extramoral, Nietzsche hace la siguiente observación:

Si alguien esconde una cosa detrás de un matorral, a continuación busca en ese mismo sitio y, además, la encuentra, no hay mucho de qué vanagloriarse en esa búsqueda y ese descubrimiento; sin embargo, esto es lo que sucede con la búsqueda y descubrimiento de la 'verdad' dentro del recinto de la razón'.

De acuerdo con ello habrá que preguntarse por la diferencia entre ese esconder y descubrir. Lo primero es, en efecto, creación, donación de sentido, interpretación; mientras que lo segundo es descripción. Pues bien, el conocimiento no se agota en uno solo de esos aspectos, pero el primero ha sido relegado por aquella 'voluntad de verdad', por aquella falta de honestidad en el conocimiento. Y con ello también lo ha sido la comprensión misma: la ciencia describe, pero no comprende. Sólo que el describir, por sí solo, carece de valor: en función de la vida es la creación lo imprescindible, incluso como presupuesto de lo primero. Así como en la intempestiva Sobre la utilidad y el perjuicio de la historia para la vida, la tesis central señala que es necesario el olvido para la vida, por lo que la historia, convertida en ciencia, constituye, por sí sola, un peligro para la vida; de la misma manera, pues, el dictamen de Sobre verdad y mentira en sentido extramoral sería que la ilusión es igualmente necesaria para la vida, por lo que la voluntad de verdad, por sí sola, resulta dañina. Más precisamente habría que decir - Nietzsche precisará esto en una etapa posterior de su pensamiento-, que ello es un síntoma de una vida que decae, de una

8 Friedrich Nietzsche, Sobre verdad y mentira en sentido extramoral, trad. Luis M. Valdés, Madrid: Tecnos 1998, p. 32. KSA, 1, p. 885.

${ }_{9}^{9}$ Nietzsche, Sobre verdad y..., p. 28. KSA, 1, p. 883. 
vida enferma, y que resulta perjudicial para una vida capaz de prosperar.

Pues bien, ¿en qué sentido es entonces la tesis de la voluntad de poder un postulado epistemológico? Nietzsche pregunta: «¿Qué es lo que únicamente puede ser el conocimiento? 'Interpretación' (Auslegung), no 'explicación' (Erklärung)» ${ }^{10}$, es decir, comprensión. La ciencia, como se ha señalado, no hace otra cosa que designar, describir el acontecer, pero sin comprenderlo. Así, «el hombre no encuentra en las cosas finalmente nada más que lo que uno mismo ha introducido en ellas: el reencontrar se llama ciencia, el introducir: arte, religión, amor, orgullo» ${ }^{11}$. A partir de esto podría incluso pensarse que la escisión de las ciencias, en ciencias del espíritu y ciencias de la naturaleza, proviene de la escisión del hombre que deriva del dualismo metafísico heredado de la tradición (materia y espíritu; cuerpo y alma - o mente-; res extensa y res cogitans; mundo de la naturaleza - o de la necesidad, o fenoménico-- y mundo de la libertad, etcétera).

Así, en tanto la tesis de la voluntad de poder tiene su blanco justamente en ese dualismo, hay que pensar que se trata de una tesis antimetafísica, pues tal dualismo constituye la cuna de la metafísica. De este modo, si sólo conocemos la 'apariencia', está de más la postulación de un mundo nouménico (dicho, de nuevo, á la Kant), de un mundo-verdadero, y deja de ser gratuita únicamente si lo que se pretende con ella entra en el ámbito de la moral, o de la razón práctica (Kant). La ciencia, incluso tal y como la conocemos hoy, presupone una interpretación del mundo, y en ese sentido la cuestión de este dualismo metafísico fundamental le afecta directamente, pues la interpretación del mundo de la que ella surge sigue siendo ésta. Para Nietzsche, esto se deja ver con claridad en

10 Nietzsche, El nihilismo..., p. 28. KSA, 12, 2 [86].

11 Nietzsche, El nihilismo..., p. 36. KSA, 12, 2 [174]. 
la interpretación de la 'regularidad de la naturaleza' en la forma de la 'legalidad': la naturaleza está sujeta a leyes universales, racionales y, por ende, congnoscibles. Esto se verá precisado más adelante, por lo pronto digamos que 'apariencia' no significa en Nietzsche, pues, falsedad, a la manera platónica (y metafísica en general), en tanto que no hay 'otra' realidad, oculta, desconocida, 'mejor'; la apariencia es la realidad. De lo que se trata entonces es de comprenderla, y ya no sólo describirla: «¿Qué se habría propiamente comprendido (begriffen) de una música si hubiésemos calculado todo lo que en ella hay de calculable y que pudiera ser abreviado en fórmulas?» ${ }^{12}$, pregunta Nietzsche, indicando a la vez cuál es el camino de la comprensión: es preciso comprender el mundo como se comprende la música. Esto es, en resumidas cuentas, desde nosotros mismos, desde la realidad básica de nuestros apetitos y pasiones, necesidades, en suma, instintos: desde el devenir mismo de los instintos (en este sentido, la posibilidad de abordar una misma cuestión desde la mayor cantidad de perspectivas posibles se convierte en la objetividad misma ${ }^{13}$ ). Se puede decir que, al menos en esto, Nietzsche seguirá siendo siempre discípulo de Schopenhauer. En efecto, dice: «¡Pertenecemos al carácter del mundo, sin ninguna duda! ¡No tenemos ningún acceso a él sino a través de nosotros $(. ..) »^{14}, \mathrm{y}$ nosotros vivimos. Pero esto no significa que el mundo mismo viva, sino que sólo a través de nuestro vivir podemos conocerlo y comprenderlo, hablar de él.

Nietzsche caracterizará este vivir como la interacción de los instintos $\mathrm{y}$, consecuentemente, de las necesidades que imperan en cada viviente, puesto que la conciencia sólo puede constituir una 'superficie', es decir, no es posible hacer depender nuestras acciones de instancias que llegan a hacerse conscientes, pues éstas constituyen lo último y lo más reducido (a la vez que interpretado), de un enorme proceso fisiológico que deriva en una acción cualquiera. La vida es así voluntad de poder, una lucha continua

12 Nietzsche, El nihilismo..., p. 60. KSA, 12, 7 [56].

13 Cf. Friedrich Nietzsche, La genealogía de la moral, trad. Andrés Sánchez Pascual, Madrid: Alianza Editorial 1997, p. 139. KSA, 5, p. 365.

14 Nietzsche, El nihilismo..., p. 25. KSA, 12, 1 [89]. 
de fuerzas. No soy yo lo que propiamente vive, sino este conglomerado de fuerzas, de instintos inconscientes. 'Yo' es un término, en última instancia, que simplifica demasiado todo eso, y en esa medida lo falsifica ${ }^{15}$, y lo hace mentirosamente (para precisar en el contexto de este trabajo). Detrás incluso de las pasiones individuales (odio, amor, por ejemplo) se encuentra esa pluralidad que, al ser caracterizada, nombrada, conscientizada, está siendo malinterpretada, esto es, simplificada (una palabra encierra algo en el fondo enormemente complejo, como en lecho de Procusto). La propia caracterización de la vida como voluntad de poder es una interpretación de aquél fondo inaprehensible e huidizo de la vida, del devenir mismo. Con lo que tocamos el asunto que nos ocupa.

\section{VI}

El aforismo 36 de Más allá del bien y del mal resume de una manera sumamente clarificadora todo lo anterior:

Suponiendo que lo único que esté 'dado' realmente sea nuestro mundo de apetitos y pasiones, suponiendo que nosotros no podamos descender o ascender a ninguna otra 'realidad' más que justo a la realidad de nuestros instintos, - pues pensar es tan sólo un relacionarse de esos instintos entre sí: - ¿no está permitido realizar el intento y hacer la pregunta de si eso dado no basta para comprender también, partiendo de lo idéntico a ello, el denominado mundo mecánico (o 'material')? ${ }^{16}$

Pues, este vivir nuestro es lo único realmente 'dado' ( «no hay hechos, solamente interpretaciones» ${ }^{17}$ ), y en esa medida es justamente ello lo real, lo único a lo que podemos llamar realidad: «Quiero decir, concebir este mundo no como una ilusión, una 'apariencia',

15 Como señala también, Marco Parmeggiani Rueda, «La ambivalencia de sentido en el lenguaje y el pensamiento de Nietzsche», en: Nietzsche bifronte, Enrique López Castellón y Julio Quesada (eds.), Madrid: Biblioteca Nueva 2005.

16 Nietzsche, Más allá del..., p. 65. KSA, 5, p. 54.

17 Nietzsche, El nihilismo..., p. 60. KSA, 12, 7 [60]. 
una 'representación' (...), sino como algo dotado de idéntico grado de realidad que el poseído por nuestros afectos (...) - como una forma previa de la vida» ${ }^{18}$. Pues bien, dirá Nietzsche enseguida, esto no sólo está permitido, sino que está mandado, «visto desde la conciencia del método» ${ }^{19}$, ya que el método constituye la verdadera victoria de la ciencia moderna. Éste exige, 'por definición':

No aceptar varias especies de causalidad mientras no se haya llevado hasta su límite extremo (...) el intento de bastarnos con una sola (...) En último término, la cuestión consiste en si nosotros reconocemos que la voluntad es realmente algo que actúa, en si nosotros creemos en la causalidad de la voluntad: si lo creemos $-\mathrm{y}$ en el fondo la creencia en esto es cabalmente nuestra creencia en la causalidad misma-, entonces tenemos que hacer el intento de considerar hipotéticamente que la causalidad de la voluntad es la única (...) Suponiendo, finalmente, que se consiguiese explicar nuestra vida instintiva entera como la ampliación y ramificación de una única forma básica de voluntad, - a saber, de la voluntad de poder, como dice mi tesis - (...), entonces habríamos adquirido el derecho a definir inequívocamente toda fuerza agente como: voluntad de poder. El mundo visto desde dentro, el mundo definido y designado en su 'carácter inteligible', - sería cabalmente 'voluntad de poder' y nada más $-{ }^{20}$.

Ahondemos un poco en la cuestión de la causalidad. En un segmento anterior del mismo libro, Nietzsche advierte que

No debemos cosificar equivocadamente 'causa' y 'efecto', como hacen los investigadores de la naturaleza [sino que] debemos servirnos precisamente de la 'causa', del 'efecto' nada más que como de conceptos puros, es decir, ficciones convencionales, con fines de designación, de entendimiento, pero no de explicación. En lo 'en-sí' no hay 'lazos causales', ni ‘necesidad' (...), allí no sigue 'el efecto a la causa', allí no gobierna 'ley' ninguna [pues no hay tal 'en-sí']. Nosotros somos los únicos que hemos inventado las causas ${ }^{21}$.

\footnotetext{
18 Nietzsche, Más allá del..., p. 65. KSA, 5, p. 54.

19 Nietzsche, Más allá del..., p. 65. KSA, 5, p. 54.

20 Nietzsche, Más allá del..., p. 66. KSA, 5, p. 54.

${ }^{21}$ Nietzsche, Más allá del..., p. 46. KSA, 5, p. 35.
} 
Esta 'cosificación' se da justamente cuando «introducimos este mundo de signos (...) ficticiamente y lo entremezclamos, como si fuera un 'en sí', en las cosas» ${ }^{22}$.

Es este cuidado el exigido por aquella honestidad, por esta 'moral del método' contrapuestos por Nietzsche a la 'voluntad de verdad' que recurre a la mentira, en lugar de asumir la ficción como tal (no como apariencia, como error), y reconocerla como ineludible. La idea de la 'legalidad' en la naturaleza es producto de esta falta de cuidado, como se puede apreciar en el fragmento citado; es una interpretación que deriva de una poco meticulosa observación de los propios procesos que conforman al cuerpo, y que conlleva la idea de la finalidad, la teleología como condición de racionalidad de la naturaleza.

Nietzsche condensa esta falta de método en lo que en el Crepúsculo de los ídolos trata como 'los cuatro grandes errores'(que son, en definitiva, errores de método): la confusión de la causa con la consecuencia (el vicio y el lujo en una sociedad es consecuencia de una degeneración fisiológica, y no al revés; la virtud es consecuencia de la felicidad, es decir, de una constitución feliz, y no al revés: «todo error, en todo sentido, es consecuencia de una degeneración de los instintos, de una disgregación de la voluntad (...) Todo lo bueno es instinto ${ }^{23}$ ); el error de la causalidad falsa (que la voluntad cause acciones: ella «simplemente acompaña a los procesos, también puede faltar ${ }^{24}$, en la misma medida que lo consciente); el error de las causas imaginarias («el reducir algo desconocido a algo conocido», lo cual «alivia, tranquiliza, satisface, proporciona además un sentimiento de poder ${ }^{25}$ ); y, por último, el error de la voluntad libre, que surge de la necesidad de juzgar y castigar, esto es, de atribuir responsabilidades, y que se reafirma en el fenómeno de la conciencia que es, sin embargo, un fenómeno superficial, en el que no encuentran eco la inmensa mayoría de los procesos instintivos (los cuales constituirían la auténtica explicación de las

22 Nietzsche, Más allá del..., p. 46. KSA, 5, p. 35.

${ }^{23}$ Friedrich Nietzsche, Crepúsculo de los ídolos, p. 69. KSA, 6, pp. 89-90.

24 Nietzsche, Crepúsculo de los..., p. 70. KSA, 6, p. 91.

${ }^{25}$ Nietzsche, Crepúsculo de los..., p. 72. KSA, 6, p. 93. 
acciones). De manera que lo estrictamente metódico consistiría en este caso en agotar las posibilidades de la ficción de la causalidad, fundamentada en nuestra creencia en la causalidad de la voluntad. Esto no sólo no afecta a la descripción científica, sino que además permite la comprensión del mundo 'mecánico'. A la interpretación de la naturaleza que entiende su regularidad (es decir, la necesidad en los acontecimientos) como 'legalidad', Nietzsche contrapone justamente la tesis de la voluntad de poder: en efecto, otra interpretación sería posible, se podría

(...) sacar de la lectura de esa misma naturaleza, y en relación a los mismos fenómenos, cabalmente el triunfo tiránico, despiadado e inexorable de pretensiones de poder (...); y que, sin embargo, afirmase acerca de ese mundo, en fin de cuentas (...) que tiene un curso 'necesario' y 'calculable', pero no porque en él dominen leyes, sino porque 'faltan' absolutamente las leyes, y todo poder saca en cada instante su última consecuencia ${ }^{26}$.

Así, la tesis de la voluntad de poder excluye la legalidad, porque parte del devenir mismo, mostrándonos un mundo en el que el azar y la necesidad reinan conjuntamente, en el que pólemos, al decir de Heráclito, es el padre de todas las cosas. Pues, si Spinoza establece que cada cosa persevera en el ser, Nietzsche dirá que cada 'cosa' tiende no a su conservación, sino al incremento de su poder, es decir, tiende a llegar a ser más, ilimitadamente (en realidad Spinoza también afirma algo similar, pero este es otro tema). Ahora bien, «es meramente cosa de la experiencia que la modificación no cesa: en sí no tenemos la más mínima razón para entender que a una modificación le tiene que seguir otra. Al contrario: un estado logrado parecería tener que conservarse a sí mismo, si no hubiera en él una facultad de - precisamente- no querer conservarse.... ${ }^{27}$. Es decir, como se señalaba, «en todo ser vivo, se puede mostrar con la máxima claridad que todo lo hace, no para conservarse, sino para llegar a ser más...» ${ }^{28}$. La vida es en

\footnotetext{
26 Nietzsche, Más allá del..., p. 48. KSA, 5, p. 37.

27 Nietzsche, El nihilismo..., p. 128. KSA, 13, 14 [121].

28 Nietzsche, El nihilismo..., p. 128. KSA, 13, 14 [121].
} 
tal sentido voluntad de poder. De otra forma, en efecto, el devenir, el cambio, la muerte misma serían inconcebibles (como de hecho han venido siendo desde el eleatismo). El poder busca el poder, concentraciones cada vez mayores de poder (en las que se es cada vez más), pero siempre en oposición, en lucha, con otras manifestaciones de poder, de modo que no hay una victoria final, ni una derrota tampoco, ninguna intención, ningún progreso. Se trata de un fluir ciego y azaroso dentro del cual, sin embargo, hasta lo más nimio es producto de la necesidad. Así, «la vida es esencialmente apropiación, ofensa, avasallamiento de lo que es extraño y más débil, opresión, dureza, imposición de formas propias, anexión y al menos, en el caso más suave, explotación - ¿mas para qué emplear siempre esas palabras precisamente, a las cuales se les ha impreso desde antiguo una intención calumniosa? $-»^{29}$. Todo lo cual define, precisamente, la voluntad de poder.

La vida misma es esa tendencia hacia concentraciones de poder (en el sentido apuntado) cada vez más vastas, por lo que es indesligable de ella la violencia y la lucha. Esta dinámica excluye, por lo demás, la posibilidad de deducir de ella una finalidad última del mundo, de la naturaleza, de la historia (a la manera de Kant, Hegel o Marx, por ejemplo). Y es que implica, en primer lugar, lo que Nietzsche denomina dionisiaco, a saber, el decir-sí a la realidad, al devenir, a la apariencia, a la ficción, que es al mismo tiempo, y esta me parece una clave importante del pensamiento de Nietzsche, una actitud vital, digamos, que conlleva o presupone la salud y la fuerza (que en breves palabras consiste en la seguridad de los instintos, que es activa), por un lado; y por otro, un postulado gnoseológico, aspecto este que ha querido ser desarrollado en este texto. Ambos aspectos son indesligables en el pensamiento de Nietzsche.

De lo anterior puede derivarse la íntima conexión que hay entre la tesis de la voluntad de poder y el pensamiento del eterno retorno de todas las cosas. En efecto, una consecuencia del perspectivismo es que todo juicio sobre el valor de la vida es absurdo 
¿Cómo podría juzgarse una totalidad de la que se es un mínimo fragmento? ¿Cómo puede juzgarse incluso un fragmento, sin juzgar al todo? En efecto, «el valor de la vida no puede ser tasado. No por un viviente, porque este es parte, es más, incluso objeto de litigio, y no juez; no por un muerto, por una razón distinta» ${ }^{30}$. Estos juicios sobre la vida, el enjuiciar mismo, tienen valor únicamente como síntomas, como manifestaciones de una forma de vida particular, de un estado fisiológico determinado.

En última instancia, es la vida misma la que expresa valores en el enjuiciamiento. «Sería necesario estar situado fuera de la vida, $\mathrm{y}$, por otro lado, conocerla tan bien como uno, como muchos, como todos los que la han vivido, para que fuera lícito tocar el problema del valor de la vida en cuanto tal ${ }^{31}$. Pero esto mismo hace un sinsentido de la exigencia de que el hombre 'mejore', o de la suposición de que lo hace. Por un lado, ello supone un juicio negativo sobre el hombre tal y como es, o sobre el animal, en todo caso sobre un fragmento de vida, ¿pero con qué barómetro se mide ese fragmento sin un previo juicio global sobre la vida (que en la mayoría de los casos es, en efecto, sólo un prejuicio)?, «no hay nada que pueda juzgar, medir, comparar, condenar nuestro ser, pues esto significaría juzgar, medir, comparar, condenar el todo... ¡Pero no hay nada fuera del todo! ${ }^{32}$. Se es un fragmento, un ángulo, un instante, una perspectiva en todo momento dentro de la existencia y dentro de la historia misma, dentro del devenir, ¿cómo podría aseverarse que ella sigue un rumbo determinado y, más aún, que se dirige hacia lo 'mejor' (por lo que todo lo anterior es 'peor)? Esto tiene, a su vez, otras implicaciones. En lo fundamental la concepción del todo y de la parte: «Decirle [a un individuo] 'modifícate' significa demandar que se modifiquen todas las cosas, incluso las pasadas...» ${ }^{33}$. Hay un nexo de necesidad entre las partes, que conforma a la totalidad:

\footnotetext{
30 Nietzsche, Crepúsculo de los..., p. 44. KSA, 6, p. 68

31 Nietzsche, Crepúsculo de los..., p. 63. KSA, 6, p. 86.

32 Nietzsche, Crepúsculo de los..., p. 76. KSA, 6, p. 96.

33 Nietzsche, Crepúsculo de los..., p. 64. KSA, 6, p. 87.
} 
Nadie es responsable de existir, de estar hecho de este o de aquel modo, de encontrarse en estas circunstancias, en este ambiente. La fatalidad de su ser no puede ser desligada de la fatalidad de todo lo que fue y será. Él no es la consecuencia de una intención propia, de una voluntad, de una finalidad ${ }^{34}$.

Cada fragmento de vida se encuentra ligado al resto por medio de sus relaciones con cada uno. En efecto, cada individuo es un conglomerado de fuerzas ligadas a la totalidad mediante sus relaciones de poder con otras fuerzas, y es a la vez producto de las relaciones entre el resto de las fuerzas: un producto necesario, tal y como es. Esta concepción devuelve al devenir, dice Nietzsche, su inocencia, y en esta misma medida es favorable a la vida, en el sentido precisado más arriba. En este sentido también hace posible el conocimiento honesto del que se ha hablado, puesto que la apariencia misma, despojada de su 'culpabilidad', y de la posibilidad incluso de ser tasada en su valor, puede ser abordada sin las pretensiones morales de las que deriva en última instancia su negación, esto es, la afirmación de un 'mundo verdadero' contrapuesto a ella.

Esto puede ser visto como una simple cuestión de método, a fin de cuentas, la aplicación de una fina navaja que desprende de la apariencia los aspectos morales y que termina por volverla comprensible.

Aquella fatalidad del devenir se encuentra condensada en una sola fórmula, la «fórmula suprema de afirmación» ${ }^{35}$, a saber, el eterno retorno de todas las cosas:

'Esta vida, tal como la has vivido y estás viviendo, la tendrás que vivir otra vez, otras infinitas veces; y no habrá en ella nada nuevo, sino que cada dolor y cada placer y cada pensamiento y suspiro y todo lo indeciblemente pequeño y grande de tu vida, te llegará de nuevo, y todo en el mismo orden de sucesión e igualmente esta araña y este claro de luna por entre los árboles, e igualmente este instante, y yo

34 Nietzsche, Crepúsculo de los..., p. 75. KSA, 6, p. 96.

35 Friedrich Nietzsche, Ecce homo, trad. Andrés Sánchez Pascual, Madrid: Alianza Editorial 2001, p. 103. KSA, 6, p. 335. 
mismo. El eterno reloj de arena de la existencia es dado vuelta una y otra vez - ¡y a la par suya tú, polvito de polvo!'36.

Este pensamiento, estrictamente hipotético, condensa la idea de que todo acontece necesariamente, de que todo acontecimiento pasado y futuro se inserta en una totalidad que no está en manos de nadie, y ni lo 'bueno' ni lo 'malo' son prescindibles; que el devenir, en suma, es inocente. El mundo se encuentra plenamente realizado en cada instante, en cada suceso, en cada cosa; no hay ni un más, ni un menos. Pero este asunto ya rebasa los límites de este trabajo.

36 Friedrich Nietzsche, La gaya ciencia, trad. Charo Greco y Ger Groot, Madrid: Ediciones Akal 2001, p. 250. KSA, 3, p. 570. 


\section{RESUMEN}

La voluntad de poder es uno de los tópicos cardinales del pensamiento de Friedrich Nietzsche, por lo mismo motivo de serios malentendidos y de una ingente cantidad de páginas. Este trabajo intenta apenas el planteamiento de una tesis, a saber, que la concepción de la voluntad de poder en Nietzsche tiene fundamentalmente el carácter de un postulado epistemológico (aunque no solamente) y no, por ejemplo, metafísico. Por último, intentarán ser mostrados, aunque con brevedad, al menos algunos de los puentes que comunican la tesis de la voluntad de poder con otro de los temas del filosofar nietzscheano que han tenido una enorme repercusión: el eterno retorno.

Palabras clave: Nietzsche, voluntad de poder, verdad, perspectivismo.

\section{ABSTRACT}

The will to power is one of the cardinal topics of Friedrich Nietzsche's thought, therefore is also occasion of serious misunderstandings and is likewise motive of an immense sum of pages. This paper attempt merely to outline this allegation: Nietzsche's thesis of will to power, fundamentally have the character of an epistemological postulate (but not only that one). That means that it is not a metaphysical thesis, as an example. Finally, I briefly will try to show at least some of the bridges between the thesis of will to power and other topic with great repercussion of Nietzsche's philosophy: eternal recurrence.

Key words: Nietzsche, will to power, truth, perspectivism. 